University of Nebraska - Lincoln

DigitalCommons@University of Nebraska - Lincoln

Uniformed Services University of the Health

Sciences

U.S. Department of Defense

2007

\title{
Electron paramagnetic resonance (EPR) in medical dosimetry
}

David A. Schauer

Uniformed Services University of the Health Sciences

Akinori Iwasaki

Dartmouth Medical School

Alexander A. Romanyukha

Uniformed Services University of the Health Sciences

Harold M. Swartz

Dartmouth Medical School

Sandro Onori

clstituto Superiore di Sanità

Follow this and additional works at: https://digitalcommons.unl.edu/usuhs

Part of the Medicine and Health Sciences Commons

Schauer, David A.; Iwasaki, Akinori; Romanyukha, Alexander A.; Swartz, Harold M.; and Onori, Sandro, "Electron paramagnetic resonance (EPR) in medical dosimetry" (2007). Uniformed Services University of the Health Sciences. 22.

https://digitalcommons.unl.edu/usuhs/22

This Article is brought to you for free and open access by the U.S. Department of Defense at DigitalCommons@University of Nebraska - Lincoln. It has been accepted for inclusion in Uniformed Services University of the Health Sciences by an authorized administrator of DigitalCommons@University of Nebraska Lincoln. 


\title{
Electron paramagnetic resonance (EPR) in medical dosimetry
}

\author{
David A. Schauer ${ }^{\mathrm{a}, *}$, Akinori Iwasaki ${ }^{\mathrm{b}}$, Alexander A. Romanyukha ${ }^{\mathrm{a}}$, Harold M. Swartz ${ }^{\mathrm{b}}$, \\ Sandro Onori ${ }^{\mathrm{c}}$ \\ ${ }^{a}$ Department of Radiology and Radiological Sciences, Uniformed Services University of the Health Sciences, Bethesda, MD 20814-4799, USA \\ ${ }^{\mathrm{b}}$ Dartmouth Medical School, EPR Center, 7785 Vail Room 702, Hanover, NH 03755, USA \\ ${ }^{\mathrm{c}}$ Istituto Superiore di Sanità, Viale Regina Elena 299, 00161, Rome, Italy
}

\begin{abstract}
This paper describes the fundamentals of electron paramagnetic resonance (EPR) and its application to retrospective measurements of clinically significant doses of ionizing radiation. X-band is the most widely used in EPR dosimetry because it represents a good compromise between sensitivity, sample size and water content in the sample. Higher frequency bands (e.g., W and Q) provide higher sensitivity, but they are also greatly influenced by water content. L and S bands can be used for EPR measurements in samples with high water content but they are less sensitive than X-band. Quality control for therapeutic radiation facilities using X-band EPR spectrometry of alanine is also presented. (C) 2007 Elsevier Ltd. All rights reserved.
\end{abstract}

\section{Introduction}

Gordy et al. (1955) first reported radiation-induced electron paramagnetic resonance (EPR) signals in irradiated skull bone almost 50 years ago. Brady et al. (1968) proposed the application of EPR spectroscopy to ionizing radiation dosimetry. Since that time, EPR dosimetry has been applied to radiation dose reconstruction, identification of irradiated food, radiation therapy, radiation processing quality assurance and archaeological dating. Tooth enamel, dentine, bone and alanine are some examples of materials successfully applied to these applications (Desrosiers and Schauer, 2001).

Until recently the use of this technology was limited to isolated samples. However, recent EPR developments have made in vivo measurements possible. This paper describes the technique and its application to retrospective measurements of clinically significant doses of ionizing radiation from unplanned exposures. This paper will also discuss the amino acid alanine and its role in ensuring accurate and precise clinical dosimetry (ISO/ASTM 51607, 2002).

\section{EPR dosimetry fundamentals}

A detailed description of EPR fundamentals and dosimetry essentials can be found in Desrosiers and Schauer (2001).

\footnotetext{
* Corresponding author. Tel.: +1 3012959806.

E-mail address: schauer@NCRPonline.org (D.A. Schauer).
}

In brief, EPR specifically and sensitively responds to the presence of unpaired electrons. Ionizing radiation generates large numbers of unpaired electron species. While most of these react immediately and disappear, in some materials in which diffusion is limited, the unpaired electrons can persist for long periods.

This phenomenon has been recognized to occur in bone and teeth (Gordy et al., 1955; Brady et al., 1968; Swartz, 1965; Swartz et al., 1965). It was shown to be a feasible method for retrospective (Brady et al., 1968; Pass and Aldrich, 1985) and radiation accident dosimetry (Schauer et al., 1993).

The concentration of radiation-induced radicals is proportional to the absorbed dose and EPR is one of the most sensitive methods to measure these radicals. This phenomenon consists of the resonance absorption of electromagnetic energy at electron-spin transitions. In order to resolve different electron-spin levels a static magnetic field is applied. In the simplest and most typical situation unpaired electrons of free radicals have spin (or magnetic moment) equal to $\frac{1}{2}$. In a magnetic field there are two magnetic levels, $+\frac{1}{2}$ and $-\frac{1}{2}$ with two different energies. The level with spin equal to $-\frac{1}{2}$ has less energy than the level with spin $+\frac{1}{2}$. The transition between these levels is possible under the following resonance condition:

$\hbar v=g \mu_{\mathrm{B}} B$, 
Table 1

Various EPR spectrometer bands

\begin{tabular}{lcc}
\hline Microwave band & Frequency $(\mathrm{GHz})$ & $B_{\text {res }}(\mathrm{mT})$ \\
\hline $\mathrm{L}$ & 1.1 & 39.2 \\
$\mathrm{~S}$ & 3.0 & 107 \\
X & $\mathbf{9 . 7 5}$ & $\mathbf{3 5 0}$ \\
$\mathrm{Q}$ & 34.0 & 1200 \\
W & 94.0 & 3400 \\
\hline
\end{tabular}

where $v$ is resonance frequency, $\hbar$ is Plank's constant, $g$ is the $\mathrm{g}$-factor, which is a constant approximately equal to 2 for spin of $\frac{1}{2}$, and $\mu_{\mathrm{B}}$ is the Bohr magnetron. An important element of this formula is a linear dependence between applied magnetic field $(B)$ and resonance frequency. Table 1 gives information on the conventional EPR bands and corresponding resonance magnetic fields, $B_{\text {res. }}$. In general as the frequency increases the sensitivity increases and the size of the sample that can be accommodated decreases. The deleterious effects on sensitivity of the presence of water also vary with frequency, generally decreasing, but having some "windows" of lowered effects at some frequencies.

$\mathrm{X}$-band is the most widely used in EPR biodosimetry because it represents a good compromise between sensitivity, sample size and water content in the sample. Higher frequency bands (W and Q) provide higher sensitivity, but they are also greatly influenced by water content. L and S bands can be used for the EPR measurements in samples with high water content but they are less sensitive than X-band.

The device for EPR registration is called an EPR spectrometer. There are four main components of an EPR spectrometer to consider:

- Electromagnet with regulated power supply to provide scanning of the resonance conditions.

- Microwave module, which consists of microwave generator, microwave cavity and detector(s).

- Signal channel, which provides amplification, processing and recording of the microwave absorption in the sample while the magnetic field scans the resonance condition.

- Magnetic field modulation, which superimposes a rapidly varying small magnet field. This usually increases sensitivity through suppression of noise by using phase sensitive detection of the modulation signal. This usually results in the output being in the form of the first derivative of the absorption curve (Fig. 1).

Every species of electronic spins has its own EPR spectrum, which is distinguished by the linewidth, shape and resonance field. The latter value is proportional to the g-factor (see Eq. (1)), which is about the same (equal to 2 ) for all $\frac{1}{2}$ spins. The peak-to-peak amplitude is usually proportional to the amount of spins, and in the case of EPR dosimetry to the radiationinduced radicals or absorbed dose.

Teeth are especially useful because the signal intensity is stronger, due to the high stability of the unpaired electrons in the hydroxyapatite matrix of the enamel. Most dosimetry studies

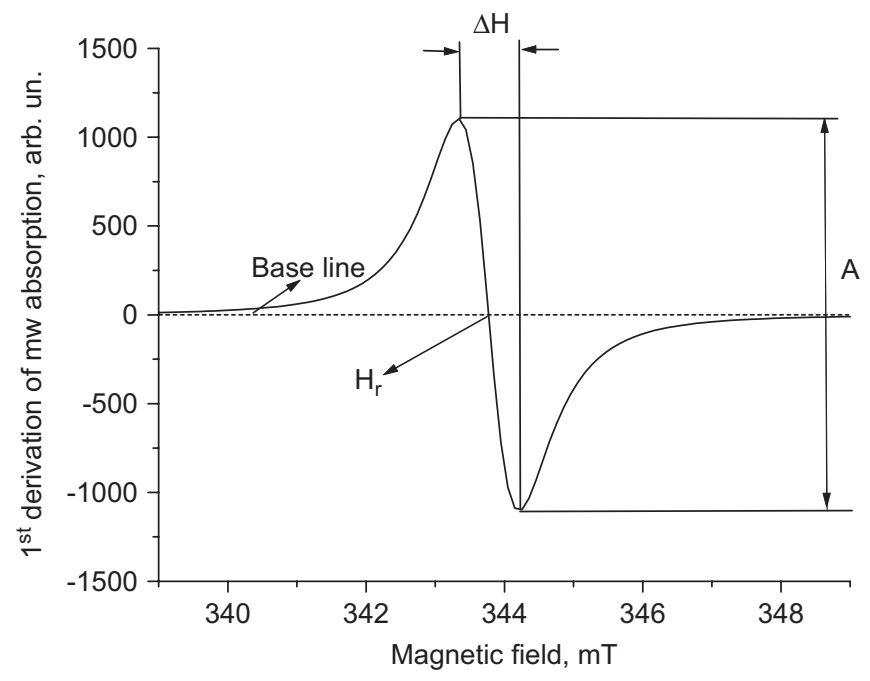

Fig. 1. EPR spectrum with definitions of some of its parameters; peak-to-peak linewidth, $\Delta H$; resonance field, $H_{\mathrm{r}}$; peak-to-peak amplitude, $A$.

based on teeth have been carried out in isolated samples at conventional EPR frequencies (e.g. $9 \mathrm{GHz}$ ). This frequency, which is referred to as X-band, has high sensitivity. Isolated teeth can be processed to enhance sensitivity, concentrating the components that have the EPR signal and removing aqueous components that lead to non-specific absorption of the microwaves. Using this approach, it has been possible to measure doses in the range of $30 \mathrm{mGy}$ in isolated teeth. This approach has been used extensively in analysis of exposures in the former Soviet Union (Chumak et al., 1998; Ishii et al., 1990; Ivannikov et al., 1997, 2002; Romanyukha et al., 1994, 1999, 2000) and for some retrospective measurements in Japan (Hoshi et al., 1985; Nakamura et al., 1998).

With the recent development of lower frequency EPR (e.g. $1 \mathrm{GHz}$ ) for making measurements in vivo with good sensitivity, it becomes possible to assess the amount of irradiated dose without tooth extraction. This is feasible because the lower frequency has greater tolerance for the presence of water and also has a relatively large sample volume. The feasibility of this approach has been shown in animals and its potential for use in human subjects was demonstrated by making measurements in isolated human teeth and comparing these measurements with isolated rat teeth and with rat teeth measured in vivo (Miyake et al., 2000).

\section{EPR medical dosimetry applications}

There are plausible circumstances in which populations potentially have been exposed to doses of ionizing radiation that could cause direct clinical effects within days or weeks, but there is no clear knowledge as to the magnitude of the exposure to individuals. It is likely that many of the individuals will not have received clinically significant doses of radiation, while others may have been exposed to performancedegrading or potentially life-threatening doses. A method that could differentiate among doses sufficiently to classify 
Table 2

Triage table for radiation effects (dose, initial symptoms and timing)

\begin{tabular}{|c|c|c|}
\hline Dose range (cGy) & Initial symptoms & Time of initial symptoms (begin/end) \\
\hline $0-75$ & $\begin{array}{l}\text { None to slight incidence of transient } \\
\text { headache and nausea. Vomiting in } \\
\text { up to } 5 \% \text { of personnel in upper part } \\
\text { of dose range. }\end{array}$ & $6 \mathrm{~h} / 12 \mathrm{~h}$ \\
\hline $75-125$ & $\begin{array}{l}\text { Transient mild nausea and vomiting } \\
\text { in } 5-30 \% \text { of personnel }\end{array}$ & $3-5 \mathrm{~h} / 1$ day \\
\hline $125-300$ & $\begin{array}{l}\text { Transient mild to moderate nausea } \\
\text { and vomiting in } 20-70 \% \text { of } \\
\text { personnel. Mild to moderate } \\
\text { fatigability and weakness in } 25-60 \% \\
\text { of personnel }\end{array}$ & $2-3 \mathrm{~h} / 2$ days \\
\hline $300-530$ & $\begin{array}{l}\text { Transient moderate nausea and } \\
\text { vomiting in } 50-90 \% \text { of personnel. } \\
\text { Mild to moderate fatigability in } 60- \\
90 \% \text { of personnel }\end{array}$ & $2 \mathrm{~h} / 3-4$ days \\
\hline $530-830$ & $\begin{array}{l}\text { Moderate to several nausea, } \\
\text { vomiting in } 80-100 \% \text { of personnel. } \\
\text { Moderate to extreme fatigability in } \\
90-100 \% \text { of personnel. }\end{array}$ & $\begin{array}{l}\text { Within the first } \\
\text { hour/days to weeks }\end{array}$ \\
\hline
\end{tabular}

Data excerpted from STANAG No. 2083, Commander's Guide on Nuclear Radiation Exposure of Groups.

individuals into categories for treatment with sufficient accuracy to facilitate decisions on medical treatment could have great benefit. Table 2 provides five dose ranges, initial symptoms and timing published by the North Atlantic Treaty Organization (STANAG 2083). Individuals with significant risk could have appropriate procedures initiated immediately, while those without a significant probability of acute effects could be reassured and removed from the need for further medical treatment. Such a division into appropriate treatment classes could be extremely valuable under circumstances such as a terrorist incident or accidental release of radiation where many people feel that they may have been exposed. The immediate measurements at the individual level would minimize panic and allow limited resources to be used more effectively.

The desirable characteristics of a method that provides an adequate solution to the problem include:

1. applicable to individuals;

2. non-invasive;

3. provide unambiguous data that are sufficient to make the differentiation into the designated dose subclasses;

4. provide the data rapidly and clearly;

5. can operate in a variety of environments;

6. can be operated by minimally trained individuals.

\subsection{EPR dosimetry results of teeth using low-frequency EPR}

While the ability of conventional EPR frequencies has been demonstrated (see Fig. 2) the ability of low-frequency EPR to make sensitive measurements in human teeth needed to be demonstrated. Miyake et al. (2000) were the first to demonstrate this capability. Fig. 3 demonstrates the type of resolution of doses that are feasible in human teeth using low-frequency
EPR with current state of the art hardware and software. Some dose-response relationships obtained with this technique are shown in Fig. 4.

\subsubsection{Low-frequency EPR spectrometer suitable for use in the human mouth}

Some of the present authors have developed an in vivo EPR system designed specifically for measuring the radiation dose in teeth in vivo. The general approach of this technique and some of the technical developmental challenges are described. It uses a lower frequency EPR spectrometer $(1.2 \mathrm{GHz})$; a specially designed resonator that will probe teeth in vivo; a magnet system that can comfortably and effectively encompass the human head; data processing to maximize sensitivity and provide an output useable by minimally trained personnel; and instrumentation that is suitable for use at the site of potential exposures.

The usual size and weight of a conventional magnet makes it difficult to meet the logistical requirements for rapid measurements and transportability, features that would be desirable for measurements of unplanned radiation exposures. This potential limitation has been overcome by using a flat magnet (McDougall and Bird; McDougall; Wagshul) with a region of sufficient homogeneity that is located appropriately in the mouth when the subject's head rests against the surface of the magnet (see Fig. 5). The weight of the magnet and its power supply is about $80 \mathrm{~kg}$, which is within the range of reasonable transportability on a cart, enabling the instrument to be brought to the site of the population that needs to be screened. Batteries can meet the modest power requirements for the magnet and the spectrometer.

The resonator is another technical challenge, because of geometric constraints for obtaining data from the mouth and the 
a

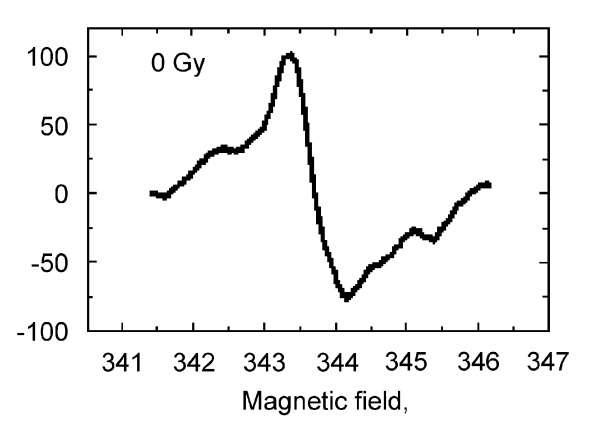

b

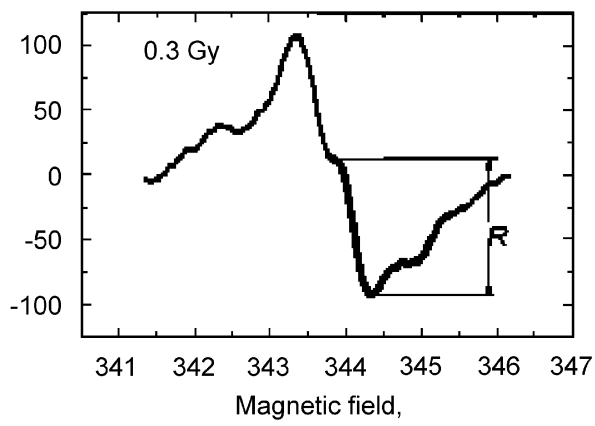

C

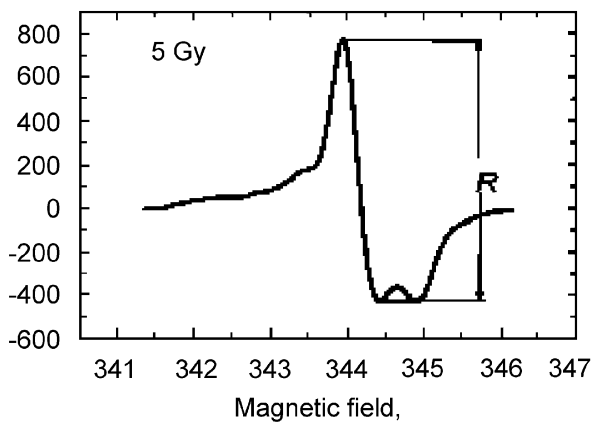

Fig. 2. X-band EPR spectra for tooth enamel irradiated to (a) 0 , (b) 0.3 and (c) 5 Gy.

\section{EPR Spectra of Human Teeth at L-band}

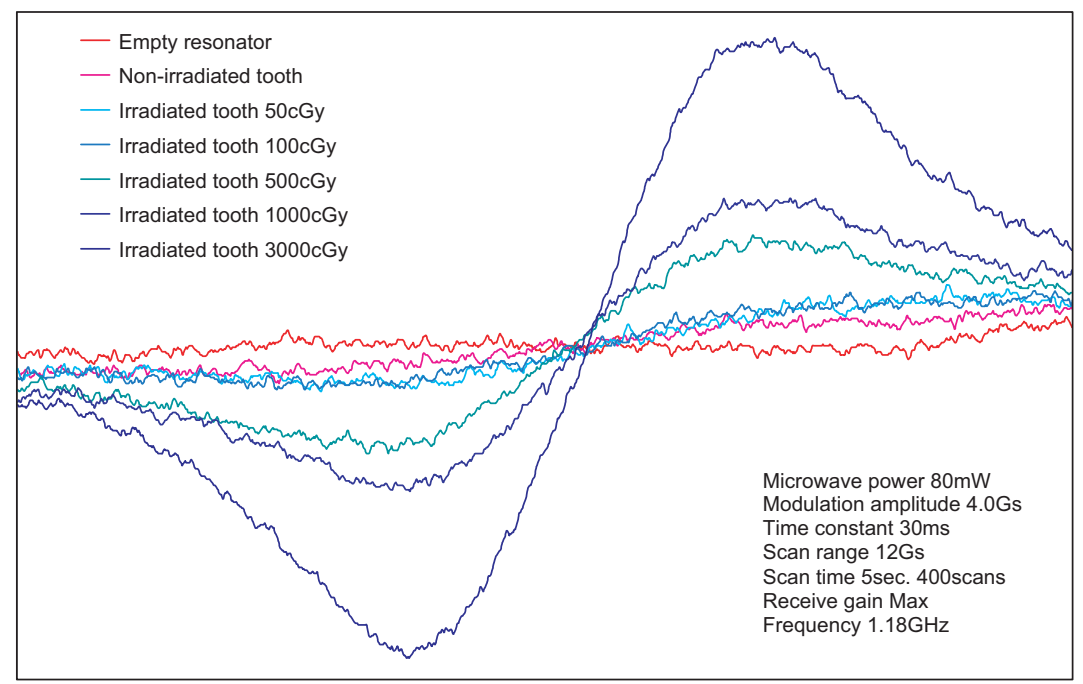

Fig. 3. EPR spectra of an empty resonator, nonirradiated and irradiated human teeth measured in L-band.

irregular shape of the teeth. Ikeya and colleagues have described the general conceptual approach, anticipating that the measurements would be made at high frequencies (Ikeya, 1993; Ikeya and Miki, 1980; Yamanaka et al., 1993). The practical steps for implementing this approach at low frequency with the requisite sensitivity have been made. The EPR signal is located principally in the enamel of the teeth, so the optimization of the sensitive volume of the resonator includes probing the maximum amount of enamel. There are several productive approaches that provide good sampling of the enamel from one to several teeth. While in principle the sensitivity and accuracy of measurements made with the apparatus using isolated teeth should be similar to those made within the mouth, there are several considerations that require that this assumption be tested rigorously. In particular, the presence of the oral structures could degrade the quality of the measurement because of effects on the microwaves that are used in the measurements. The initial tests in which the same resonator was used to measure the same tooth gave a similar response within the mouth as on the lab bench. The signal to noise ratio of this 


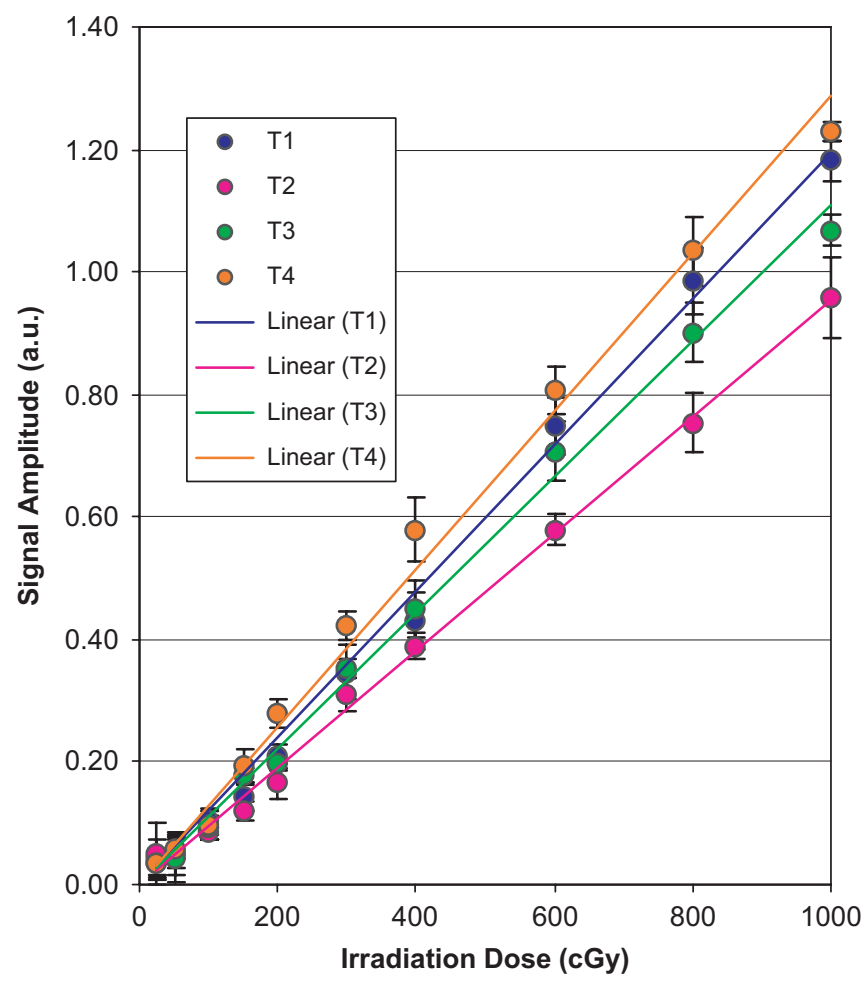

Fig. 4. Dose-response relationship for L-Band measurements of human teeth before normalization for tooth size. measurement was less within the mouth, but in view of the fact that this was the first such measurement and that there are a number of factors that can be further optimized, this result indicates that measurements within the mouth will be comparable to those already achieved outside of the mouth.

A third area of technical challenge is the need to optimize a weak signal, which includes an overlapping background signal. With isolated teeth, the dose-response for the tooth can be determined with the use of added calibrated doses, with extrapolation back to the original dose. This option, of course, cannot be used with teeth in vivo. Instead, we have measured the responses of a large number of teeth to provide a library that can be used to estimate the dose directly. To differentiate between the background signal and the radiation-induced signal, measurements are performed at two different microwave powers for which the two signals have the greatest difference in power saturation. The output will be in the form of a specific dose with a specific estimate of the uncertainty. Making simultaneous measurements at three sites within the mouth will enhance the accuracy.

In its current state, the in vivo EPR dosimetry system can provide estimates of absorbed dose of $\pm 0.25 \mathrm{~Gy}$ in the range of $0.5-1000 \mathrm{cGy}$. This is expected to improve, with improvements in the resonator, the algorithm for calculating dose, and the uniformity of the magnetic field. In its current state of development, it probably is sufficient for most applications

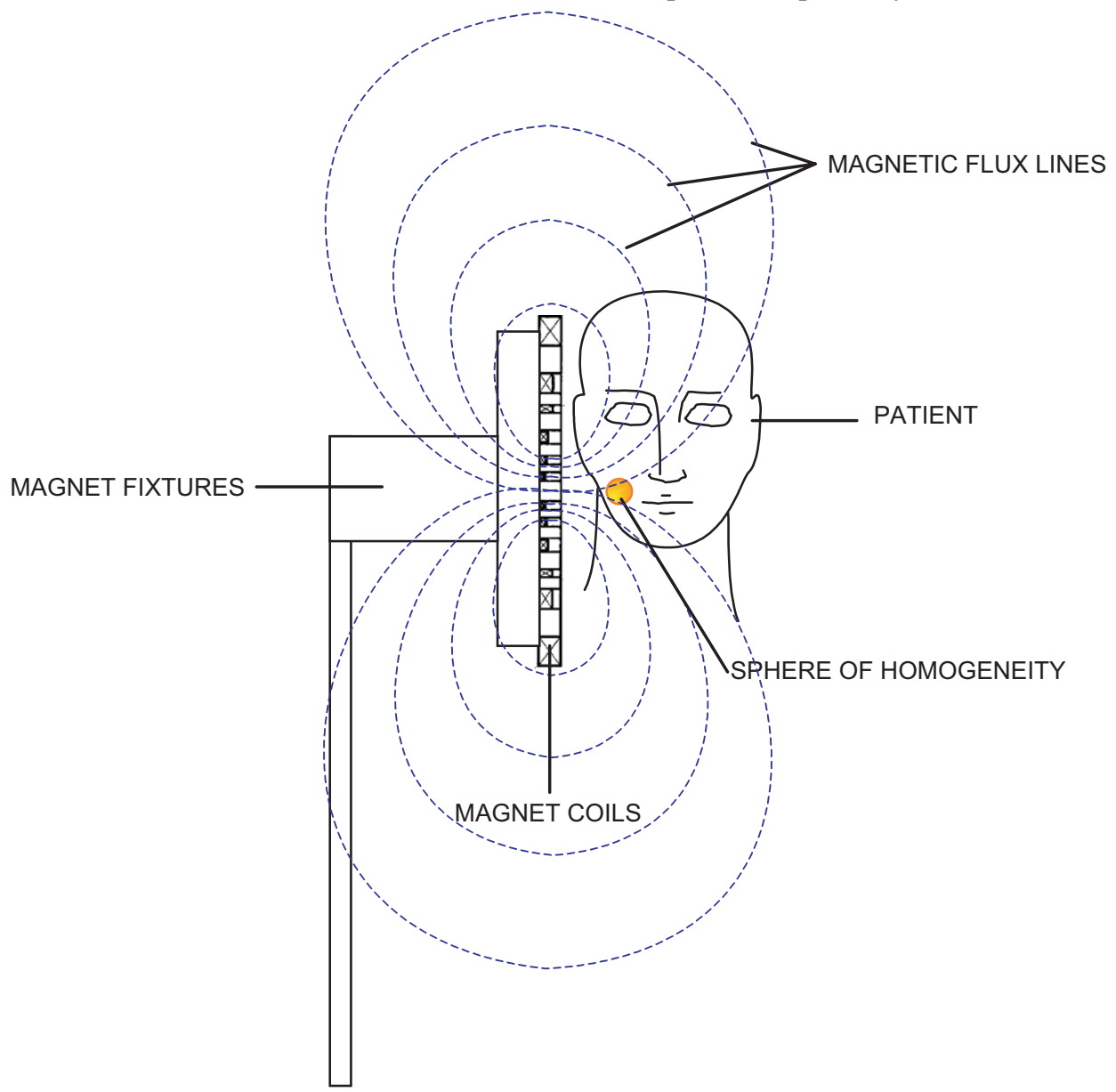

Fig. 5. Schematic of flat magnet concept and patient orientation as realized by Resonance Research, Inc. 
related to terrorism or nuclear warfare, for decision-making for action for individuals in regard to acute effects from exposure to ionizing radiation.

\section{Quality control for therapeutic radiation facilities using EPR spectrometry of alanine}

The Italian National Institute of Health (ISS), in the framework of continuous quality improvement programmes in radiotherapy is coordinating various postal dosimetry intercomparisons among radiotherapy centers to evaluate any differences between stated and measured doses for various radiotherapy modalities. Doses are measured by ISS, acting as the reference center.

Dosimetry intercomparison requires a proper measurement system operated by a well-recognized reference body. TLDs are used world-wide (IAEA, ESTRO, USA, UK) as transfer standards because of reliability, low uncertainty and easy distribution through the mail.

However, the ISS has pioneered the use of alanine as part of their radiation therapy quality assurance program. The choice of alanine was made on the basis of the positive alanine characteristics, which include low uncertainty, tissue equivalence, dose rate and energy independence, high stability of the response, small dimensions, non-destructive readout procedure, and mailability. These characteristics give alanine a high potential for medical applications.

The radiation dosimeter is prepared using $\alpha$-alanine, $\mathrm{CH}_{3}-\mathrm{CH}\left(\mathrm{NH}_{2}\right)-\mathrm{COOH}$, in the form of polycrystalline powder. The most commonly used form is L-alanine, however, both stereosiomers are useful for absorbed dose measurements (ISO/ASTM, 2002). Fig. 6 is a typical EPR spectrum or irradiated alanine. The radiation-induced signal intensity, $S$, is proportional to the absorbed dose.

The EPR spectrometer used to analyze the alanine should be capable of the following settings:

- Microwave frequency 9 to $10 \mathrm{GHz}$ with automatic field frequency locking.

- Corresponding magnetic field to set a g-factor of 2.0 (at $9.8 \mathrm{GHz}$, this equals $350 \mathrm{mT}$ ) with a field scan range of $20 \mathrm{mT}$ about the center field.

- Radiofrequency modulation amplitude 0.1-1 mT.

- Microwave power 0.1-10 mW (leveled).

- Variable sweep time, time constant, and receiver gain dependent on absorbed dose.

- Sensitivity of the spectrometer should be at least $2 \times$ $10^{11}$ spins/mT.

- Cavity should have a sample access diameter of at least $1 \mathrm{~mm}$ greater than the diameter of the dosimeter being analyzed.

The combination of the growth of sites where radiation therapy is being carried out and the increasing sophistication of the methods by which therapeutic radiation is delivered highlights the importance of independent quality control. Clinical audits are generally considered of primary importance in improving quality in the radiotherapy process. They are accepted

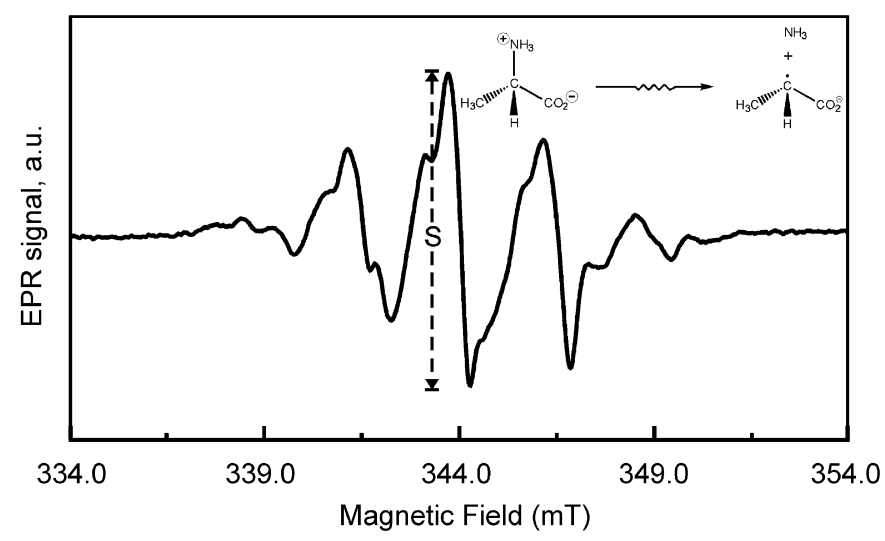

Fig. 6. EPR spectrum of irradiated alanine.

as a potential tool in the complex sequence involved in patient treatment and to find systematic errors in dose delivery.

Other clinical applications of EPR spectrometry of alanine include brachytherapy (De Angelis et al., 1999), proton therapy (Nichiporov et al., 1995; Onori et al., 1997), electron arc therapy treatment planning verification (De Angelis et al., 2000) and total body irradiation (Indovina et al., 1989).

\section{Other applications and future developments}

Desrosiers et al. (1993) reported on the results of measurements of radiopharmaceutical absorbed doses. Therapeutic and palliative uses of bone-seeking radiopharmaceuticals have undergone clinical trials for human subjects. Radiation dosimetry for these applications is based on the Medical Internal Radiation Dosimetry (MIRD) schema. An experimental method for dosimetry of bone tissue based on EPR spectrometry has been validated. Results for beagle bone exposed to radiopharmaceuticals under clinical conditions indicated that these measurements give approximately the calculated dose, but suggest that the dose distribution may be non-uniform.

There are many aspects to the types of quality control measures that are needed, and no single method will cover all of them. In vivo EPR dosimetry does appear to have the potential for covering one important aspect: after-the-fact monitoring of the accuracy of calculated dose distribution.

The approach would be selective to monitor patients who have received radiation treatments that include significant doses to the teeth. The accuracy of the combination of the delivery of the dose and the calculation of its distribution in the oral cavity could readily be checked retrospectively by measurements of the EPR signals in the teeth. Several different teeth could be measured, providing data on the distribution of dose within the oral cavity. By selecting patients that have had relatively large doses to the teeth, the accuracy of the measurements by EPR should be at least $\pm 5 \%$. While this clearly would provide measurements only on a limited number of patients with a limited range of conditions, the measurements should be a valid indicator of the overall level of performance of the facility. This approach would have the very significant advantage 
of having the measurement being completely objective and independent of any measurements by the facility for the quality control aspect. No dosimeters would need to be put in place and there should be no possibility of errors in the placement of the dosimeters. Once the treatment is completed, the signals in the teeth persist indefinitely, so there would be no time constraints as to when the measurements were made. If potential problems would be identified in the measurements, the monitoring could be extended to additional patients whose radiation treatment had the appropriate characteristics.

Other promising research is being conducted with Q-band (35 GHz) EPR measurements on small $(\sim 10 \mathrm{mg})$ tooth samples. The potential advantages of this approach are the minimally invasive nature of the sample extraction and enhanced spectral resolution.

\section{References}

Brady, J.M., Aarestad, N.O., Swartz, H.M., 1968. In vivo dosimetry by electron spin resonance spectroscopy. Health Phys. 15, 43-47.

Chumak, V., Likhtarev, I., Sholom, S., Meckbach, R., Krjuchkov, V., 1998. Chernobyl experience in field of retrospective dosimetry: reconstruction of doses to the population and liquidators involved in the accident. Radiat. Prot. Dosimetry 77, 91-95.

De Angelis, C., Onori, S., Petetti, E., Piermattei, A., Azario, L., 1999. Alanine/EPR dosimetry in brachytherapy. Phys. Med. Biol. 44, 1181-1191.

De Angelis, C., Mattacchioni, A., Onori, S., Aragno, D., de Paula, U., Panichelli, V., 2000. Electron arc therapy treatment planning verification with alanine/EPR dosimetry. Appl. Radiat. Isot. 52, 1203-1207.

Desrosiers, M.F., Schauer, D.A., 2001. Electron paramagnetic resonance (EPR) biodosimetry. Nucl. Instrum. Methods B 184/1-2, 219-228.

Desrosiers, M.F., Avila, M.J., Schauer, D.A., Coursey, B.M., Parks, N.J., 1993. Experimental validation of radiopharmaceutical absorbed dose to mineralized bone tissue. Appl. Radiat. Isot. 44, 459-463.

Gordy, W., Ard, W., Shields, H., 1955. Microwave spectroscopy of biological substances. Paramagnetic resonance in $\mathrm{X}$-irradiated amino acids and proteins. Proc. Nat. Acad. Sci. USA 41, 983-996.

Hoshi, M., Sawada, S., Ikeya, M, Miki, T., 1985. ESR dosimetry for A-bomb survivors. ESR dating and dosimetry. Ionic, Tokyo, 407-414.

Ikeya, M., 1993. New Application of Electron Spin Resonance-Dating, Dosimetry and Microscopy. World Scientific, Singapore.

Ikeya, M., Miki, T., 1980. Electron spin resonance dating of animal and human bones. Science 207, 977-979.

Indovina, P.L., Benassi, M., Giacco, G.C., Primavera, A., Rosati, A., 1989 In vivo ESR dosimetry in total body irradiation. Strahlentherapie und Onkologie-Organ der Deutschen Rontgengesellschaft 165, 611-616.

International Organization for Standardization/American Society for Testing and Materials (ISO/ASTM 51607-2002). Standard Practice for Use of the Alanine-EPR Dosimetry System.

Ishii, H., Ikeya, M., Okano, S., 1990. ESR dosimetry of teeth of residents close to the Chernobyl reactor accident. J. Nucl. Sci. Tech. 27, 1153-1155.
Ivannikov, A., Skvortzov, V.G., Stepanenko, V.F., Tikunov, D.D., Fedosov, I.M., Romanyukha, A.A., Wieser, A., 1997. Wide-scale EPR retrospective dosimetry: results and problems. Radiat. Prot. Dosimetry 71, 175-180.

Ivannikov, A., Zhumadilov, Zh., Gusev, B., Miyazawa, C., Liao, L., Skvortsov, V.G., Stepanenko, V.F., Takada, J., Hoshi, M., 2002. Individual dose reconstruction among residents living in the vicinity of the Semipalatinsk Nuclear Test Site using EPR spectroscopy of tooth enamel. Health Phys. 83, 183-196.

McDougall, I.L. Magnet assembly. US PATENT 4,985,678.

McDougall, I.L., Bird, J.M. Magnet assembly having a plurality of nested coils. US PATENT 4,701,736.

Miyake, M., Liu, K.J., Walczak, T., Swartz, H.M., 2000. In vivo dosimetry of accidental exposures to radiation: experimental results indicating the feasibility of practical use in human subjects. Appl. Radiat. Isot. 52, 1031-1038.

Nakamura, N., Miyazawa, C., Akiyama, M., Sawada, S., Awa, A.A., 1998. A close correlation between electron spin resonance (ESR) dosimetry from tooth enamel and cytogenetic dosimetry from lymphocytes of Hiroshima atomic-bomb survivors. Int. J. Radiat. Biol. 73, 619-627.

Nichiporov, D., Kostjuchenko, V., Puhl, J., Bensen, D., Desrosiers, M., Dick, C., McLaughlin, W., Kojima, T., Coursey, B., Zink, S., 1995. Investigation of applicability of alanine and radiochromic detectors to the dosimetry of proton clinical beams. Appl. Radiat. Isot. 45, 1355-1362.

Onori, S., d'Errico, F., De Angelis, C., Egger, E., Fattibene, P., Janovsky, I., 1997. Alanine dosimetry of proton therapy beams. Med. Phys. 24, 447-453.

Pass, B., Aldrich, J.E., 1985. Dental enamel as an in vivo radiation dosimeter. Med. Phys. 12, 305-307.

Romanyukha, A.A., Regulla, D., Vasilenko, E., Wieser, A., 1994. South Ural nuclear workers: comparison of individual doses from retrospective EPR dosimetry personal monitoring. Appl. Radiat. Isot. 45, 1195-1199.

Romanyukha, A.A., Ignatiev, E.A., Ivanov, D.V., Vasilyev, A.G., 1999. The distance effect on the individual exposures evaluated from the Soviet nuclear bomb test at Totskoye test site in 1954. Radiat. Prot. Dosimetry 86, 53-58.

Romanyukha, A.A., Ignatiev, E.A., Vasilenko, E.K., Drozhko, E.G., Wieser, A., Jacob, P., Keriim-Markus, I.B., Kleschenko, E.D., Nakamura, N., Miyazawa, C., 2000. EPR dose reconstruction for Russian nuclear workers. Health Phys. 78, 15-20.

Schauer, D.A., Coursey, B.M., Dick, C.E., McLaughlin, W.L., Puhl, J.M., Desrosiers, M.F., Jacobson, A.D., 1993. A radiation accident at an industrial accelerator facility. Health Phys. 65, 131-140.

Standardization Agreement (STANAG) 2083. Commander's Guide on Nuclear Radiation Exposure of Groups.

Swartz, H.M., 1965. Long-lived electron spin resonances in rats irradiated at room temperature. Radiat. Res. 24, 579-586.

Swartz, H.M., Molenda, R.P., Lofberg, R.T., 1965. Long-lived radiationinduced electron spin resonances in an aqueous biological system. Biochem. Biophys. Res. Comm. 21, 61-65.

Wagshul, M. Magnetic resonance apparatus and method of shim adjustment. US PATENT 6,208,142.

Yamanaka, C., Ikeya, M., Hara, H., 1993. ESR cavities for in vivo dosimetry of tooth enamel. Appl. Radiat. Isot. 44, 77-80. 